\title{
Vascular Heat Shock Protein Expression in Response to Stress

\author{
Endocrine and Autonomic Regulation of this Age-dependent Response
}

Robert Udelsman, * Michael J. Blake, Carole A. Stagg, * Ding-gang Li, * D. James Putney, and Nikki J. Holbrook

* Division of Endocrine Surgery, The Johns Hopkins Hospital, Baltimore, Maryland 21287; and Laboratory of Molecular Genetics, Gerontology Research Center, National Institute on Aging, Baltimore, Maryland 21224

\begin{abstract}
Adaptation to stress requires coordinated interactions between the vascular and endocrine systems. Previously we demonstrated that restraint stress induces the expression of the major heat shock protein, HSP70, in the adrenal cortex of the rat. Here we demonstrate that restraint also induces expression of HSP70 in the vasculature. We further demonstrate that the adrenal and vascular responses are differentially regulated: the adrenal response is adrenocorticotropin dependent, whereas the vascular response is under adrenergic control. In addition, the adrenal response is restricted to members of the HSP70 gene family, whereas in vascular tissue the low molecular weight HSP, HSP27, is also induced by restraint. Further characterization of the vascular response revealed that HSP70 induction occurred in both the thoracic and abdominal aortas as well as in the vena cava. However, no HSP70 induction was apparent in the heart or in a wide variety of other tissues examined. In situ hybridization showed that the vascular expression was localized to the aortic smooth muscle cells with minimal expression in the endothelium. Induction of HSP70 mRNA in both the adrenal cortex and aorta was followed by an elevation in HSP70 protein. Maximum HSP70 protein levels were seen within 3-12 h after restraint, but declined thereafter. Stress induced HSP70 expression was dramatically reduced with age, which may explain, in part, the diminished tolerance to stress seen in elderly individuals. (J. Clin. Invest. 1993.91:465-473.) Key words: adrenergic regulation • aging • heat shock protein • stress • vascular stress response
\end{abstract}

\section{Introduction}

The mammalian stress response evokes a series of neuroendocrine responses that result in activation of the hypothalamic-pituitary-adrenal (HPA) ${ }^{1}$ axis and the sympathetic nervous system $(1,2)$. Interactions between these stress response systems occur at multiple levels including the brain, pituitary gland, adrenal gland, and peripheral blood vessel (3). These interac-

Address reprint requests to Dr. Robert Udelsman, Division of Endocrine Surgery, The Johns Hopkins Hospital, Osler 624, 600 N. Wolfe Street, Baltimore, MD 21287.

Received for publication 28 May 1992 and in revised form $18 \mathrm{Au}$ gust 1992.

1. Abbreviations used in this paper: HPA, hypothalamic-pituitaryadrenal; HSP, heat shock protein.

J. Clin. Invest.

(C) The American Society for Clinical Investigation, Inc.

0021-9738/93/02/0465/09 \$2.00

Volume 91, February 1993, 465-473 tions result in improved cardiovascular dynamics that enhance homeostasis (4).

At the cellular level, stress results in the synthesis of a family of proteins termed heat shock proteins (HSPs) $(5,6)$. Though originally named on the basis of their induction after heat stress, HSPs are representative of a more generalized response to environmental and/or metabolic stressors. The ubiquitous nature of the heat shock response as well as its phylogenetic conservation suggests that the HSPs are essential for survival during or after stress (7). Many HSPs are also expressed constitutively in the absence of stress and thus appear to play a vital role in normal cellular processes. Although the specific functions of all of the HSPs remain to be elucidated, there is evidence that several HSPs interact with other cellular proteins to assist in protein assembly, disassembly, stabilization, or transport $(8,9)$. Interestingly, both HSP70 and HSP90 function as molecular chaperones assisting with the translocation of the glucocorticoid receptor from the cytosol to the nucleus (10).

Most of our knowledge concerning the homeostatic role of HSPs has come from studies on cultured cells (11-13). Much less is known about their expression in vivo, although it is clear that HSPs are induced in the intact animal in response to localized injury (spinal cord trauma, head injury, or reperfusion injury) and systematically after heat stress (14-16). Elevated levels of HSPs also occur in certain chronic disease states in humans (17-19). Previously, we reported that restraint, a mild physiologically relevant stress, induces HSP70 mRNA expression in the adrenal cortex of the rat (20). The response was shown to be dependent on an intact HPA axis and to be mediated by adrenocorticotropic hormone (ACTH). We have also demonstrated that HSP70 mRNA induction occurs after moderate surgical stress in both the adrenal cortex and the vasculature, but not in any other of a dozen tissues examined (21). This vascular response, which may have broad ramifications, has not been well characterized.

Accordingly, we examined whether HSP expression is also induced in the vasculature in response to restraint stress. We demonstrate that restraint results in marked induction of both HSP70 and HSP27 mRNA in the vasculature of the rat. This rodent restraint model was used to further characterize this vascular stress response in conscious animals. We sought to determine $(a)$ the endocrine regulation of this response, $(b)$ the relationship between mRNA induction and HSP70 protein expression, $(c)$ the anatomic localization of HSP70 expression within the vasculature, and $(d)$ the effects of aging upon this response.

\section{Methods}

Animals. Adult male Wistar rats ranging in age from 6 to 7 mo were obtained from the Gerontology Research Center Animal Colony. This colony is fully accredited by the American Association for Accredita- 
tion of Laboratory Animal Care and is monitored for viral, bacterial, and parasitic infection. 6-mo (young adult) and 24-mo (old) male Fischer 344 rats were obtained from the animal colony maintained by Charles River Breeding Laboratory (Wilmington, MA) for the National Institute on Aging. All animals were acclimated in individual cages at the Gerontology Research Center for at least $1 \mathrm{wk}$ before experimentation and were maintained on a light/dark $(12 \mathrm{~h} / 12 \mathrm{~h})$ cycle at $24^{\circ} \mathrm{C}$ and given food and water ad libitum except during experiments. All procedures were performed according to protocols approved by the responsible institutional committees in accordance with guidelines established by the National Institutes of Health.

Restraint model. Conscious rats were restrained by placement in clear ventilated plexiglass chambers for a 60 -min interval under normothermic conditions between 0800 and $0900 \mathrm{~h}(20)$. After this stress or immediately upon removal from their holding facility (control group) the animals were killed by decapitation. Trunk blood was collected for subsequent radioimmunoassays and the aortas, vena cavas, and adrenal glands were harvested. In limited experiments addressing the specificity of the response, a variety of additional tissues were also removed.

RNA extraction and Northern analysis. Freshly harvested tissues were homogenized and the RNA was extracted with RNAzol B (Cinnabiotex, Friendswood, TX). Total RNA ( $10 \mu \mathrm{g}$ per lane) was fractionated by electrophoresis on formaldehyde-agarose gels and transferred to nylon membranes (Gene Screen Plus, DuPont, Boston, MA). Hybridizations were performed using a ${ }^{32} \mathrm{P}$-labeled cDNA HSP70 probe as previously described (22). Accuracy of loading and transfer was confirmed by hybridization with an $18 \mathrm{~s}$ specific oligonucleotide probe. HSP27 and HSP89 $\beta$ (HSP90) cDNAs were obtained from StressGen Biotechnologies Corp. (Sidney, BC, Canada) and were labeled with the random primer oligonucleotide technique using $\alpha$ - $\left[{ }^{32} \mathrm{P}\right] \mathrm{dCTP}$ according to the manufacturers recommendations. Autoradiographs of the blots were obtained in the linear range of detection and were quantified for the levels of specific expression by scanning laser densitometry (Ultrascan XL, LKB Produkter, Bromma, Sweden) of autoradiographs.

Western analysis. Freshly harvested tissues were frozen in liquid nitrogen, pulverized, reconstituted in dd $\mathrm{H}_{2} \mathrm{O}$, and freeze-thawed four times. Cytosolic proteins were isolated from supernatant fractions after homogenization and centrifugation $(5,000 \mathrm{rpm}, 5 \mathrm{~min})$ of tissue samples. Protein was quantitated and equal amounts from six separate animals per time point were pooled and added to $2 \times$ SDS, boiled ( 4 $\mathrm{min}$ ), and fractionated on polyacrylamide gels (23). After electrophoresis, the proteins were transferred to nitrocellulose and Western immunoblotting was performed using a mouse monoclonal antibody $(1 \mu \mathrm{g} /$ $\mathrm{ml}$, StressGen Corp., Victoria, Canada) specific for inducible HSP70 (24). Sheep anti-mouse IgG horeradish peroxidase-linked antibody $(1: 3,000)$ (Amersham Corp., Arlington Heights, IL) was used to form protein-antibody complexes which were detected with a chemiluminescent reaction (ECL Western blot, Amersham Corp.), after exposure to XAR-2 diagnostic film (Eastman Kodak Co., Rochester, NY).

Hypophysectomy model. Adult male Wistar rats underwent acute hypophysectomy and were maintained on daily intramuscular ACTH injections $(0.25 \mu \mathrm{g} / \mathrm{d} ; 0.25 \mathrm{U} / \mathrm{d})$ for $10 \mathrm{~d}$. On the 11 th day the animals received an intramuscular injection of saline, dexamethasone $(20 \mu \mathrm{g})$, or ACTH $(0.25 \mathrm{U})$ and either underwent a 60 -min restraint interval or were left in their holding facility for $60 \mathrm{~min}$ of "nonrestraint." The animals were then killed, the adrenal glands were weighed, and total RNA was extracted from the adrenal glands and aortas.

Adrenergic manipulation model. In order to test the effects of adrenergic receptor blockade upon HSP70 expression, groups $(n=8$ per group) of male Wistar rats (6-8 mo) received an acute intraperitoneal injection of either saline, the $\alpha_{1}$-adrenergic blocking agent, prazo$\sin (1 \mathrm{mg} / \mathrm{kg})$, or the $\beta$-adrenergic blocking agent, propranolol (20 $\mathrm{mg} / \mathrm{kg}$ ). After drug (or saline) administration the animals remained in their holding facility for $30 \mathrm{~min}$ and were then subjected to restraint stress for $60 \mathrm{~min}$ as described above.

In vivo adrenergic stimulation model. Adult male Wistar rats underwent insertion of polyethylene catheters via the common femoral vein into the inferior vena cava under thiopental $(40 \mathrm{mg} / \mathrm{kg}$ i.m. $)$ anesthesia. The catheters were tunneled through the subcutaneous tissue, to exit from the back where they were connected to a swivel device (Rodent Multi-fluid Channel Swivel, Stoelting Co., Wood Dall, IL). This model allows for complete animal mobility so that subsequent experiments could be performed in conscious, nonrestrained animals. $1 \mathrm{wk}$ after catheter insertion the specific $\alpha_{1}$-adrenergic agonist, phenylephrine $(0.14 \mathrm{mg} / \mathrm{kg})$, was administered via the catheter into the vena cava. $1 \mathrm{~h}$ after phenylephrine (or saline) administration the animals were killed, the aortas were harvested, and the aortic total RNA was probed for HSP70 mRNA. The dose of the phenylephrine was calculated on a milligram per kilogram basis to be equivalent to the dose administered to a human patient experiencing hypotension secondary to alpha receptor blockade (25). Six animals were used per group.

To determine if this dose of phenylephrine had significant hemodynamic effects, another group of rats ( $n=6$ per group) underwent light anesthesia with thiopental $(40 \mathrm{mg} / \mathrm{kg}$ i.m.) followed by insertion of polyethylene catheters via the common femoral artery and vein into the abdominal aorta and inferior vena cava, respectively. The aortic catheter was connected to a pressure transducer (COBE, Lakewood, $\mathrm{CO}$ ) and a blood pressure analyzer (Micro-MED, Inc., Louisville, $\mathrm{KY}$ ). A bolus injection of phenylephrine or saline was then administered via the vena cava catheter and hemodynamic measurements were made every $10 \mathrm{~s}$ for the first $5 \mathrm{~min}$ and every min thereafter for $60 \mathrm{~min}$.

In situ hybridization. Freshly harvested aortas from restraint and control animals were frozen, sectioned $(14 \mu \mathrm{m})$, and placed side by side on individual slides so that hybridizations could be performed under a single coverslip. Hybridizations were performed with an ${ }^{35} \mathrm{~S}$-labeled synthetic oligonucleotide ( $5^{1}$ CGATCTCCTTCATCTTGGTCAGCACCATGG- ${ }^{1}$ ) that selectively recognizes induced HSP70 transcripts in the rat (14). This oligonucleotide is complementary (antisense) to the transcribed mRNA sequence of the human HSP70 gene encompassing amino acids 21-30 (26). Hybridizations were performed as previously described (27). After hybridization $(24 \mathrm{~h})$ the slides were immersed in photographic emulsion (Kodak NTB2), dried, and stored for $2 \mathrm{wk}$ before development and washing. Specificity of hybridization was tested by each of the following: $(a)$ treatment with 100 -fold excess cold oligonucleotide, $(b)$ pretreatment of slides with RNase prior to hybridization, and $(c)$ hybridization with a labeled oligonucleotide complementary (sense strand) to the sequence given above.

Hormone assays. Trunk blood was collected in prechilled EDTA tubes. Samples were centrifuged within $20 \mathrm{~min}$ to recover plasma which was stored at $-80^{\circ} \mathrm{C}$. ACTH and corticosterone were extracted from the plasma (Sep-Pak C18 cartridge, Waters Associates, Milford, MA) and measured by radioimmunoassay as previously described (28). All samples were analyzed in duplicate in a single assay to eliminate interassay variation. The intra-assay coefficients of variation and assay sensitivities were $6.5 \%$ and $25 \mathrm{pg} / \mathrm{ml}$ for ACTH and $10.6 \%$ and $0.3 \mu \mathrm{g} / \mathrm{dl}$ for corticosterone.

Statistical analysis. Five to eight animals were examined for each experimental condition. Results are expressed as the mean \pm SEM. Analysis of variance (ANOVA) was performed when more than two groups were compared, and when significant $(P<0.05)$, a NewmanKeuls multiple comparison test was applied to test for differences between individual groups (29). When two groups were compared a twotailed Student's $t$ test was applied.

\section{Results}

\section{Induction of HSP expression in adrenals and aortas of restrained rats.}

Northern analysis was used to examine the relative level of expression of different HSP70 mRNA transcripts in the adrenals and aortas of control (C; unrestrained) rats, and rats exposed to 60 min of restraint $(R)$. In the absence of stress, only a single $2.3-\mathrm{kb}$ transcript, corresponding to the constitutively ex- 

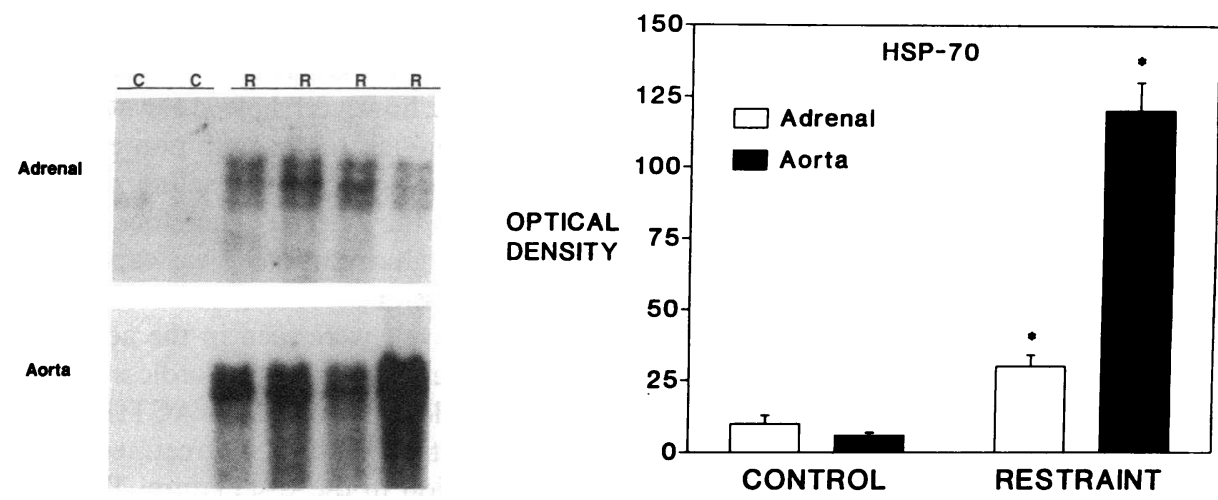

Figure 1. Induction of HSP70 mRNA in adrenal and aortic tissue of rats after restraint stress. (Left) Representative Northern blot of HSP70 expression in total RNA ( $10 \mu \mathrm{g}$ per lane) of adrenal glands and aortas harvested from individual male Wistar rats after either 60 min of restraint $R$ in ventilated plexiglass chambers or immediately upon removal from their holding facility $C$. (Right) Summary of results comparing adrenal and aortic HSP70 mRNA expression in groups ( $n=6$ per group) of control (nonrestraint) or restraint stressed male Wistar rats. Results are expressed as the mean \pm SEM relative optical density for the induced HSP70 transcripts. ${ }^{*} P<0.05$, by a two-tailed student's $t$ test compared to the control group.

pressed HSP70 gene (HSC70) (26), was observed in either tissue (Fig. 1). Basal levels of this transcript were higher in the adrenal gland than in the aorta of unstressed rats, but in both tissues the magnitude of expression increased after restraint. In addition, restraint resulted in the appearance of two additional higher molecular weight transcripts which correspond to stressinducible members of the HSP70 gene family in the rat (26). The magnitude of the aortic HSP70 induction exceeded that of the adrenal (Fig. 1, left). The level of HSP70 induction was quantified by laser densitometry of Northern blots obtained from six control and six restraint-stressed animals. Accuracy of loading and transfer was confirmed by hybridization with an $18 \mathrm{~s}$ specific oligonucleotide probe. The results are expressed as the mean \pm SEM level of HSP70 induction and a two-tailed student's $t$ test was used to compare restraint and control groups (Fig. 1, right).

The vascular response was not limited to the arterial circulation as HSP70 expression was also induced in the vena cavas of restrained animals (Fig. 2). However, no induction of HSP70 expression occurred in the hearts of the stressed animals (not shown). Other tissues that failed to demonstrate a stress-induced increase in HSP70 mRNA expression included the brain, pituitary, thyroid, lung, liver, kidney, small bowel, gracilis muscle, spleen, and thymus. Multiple RNA blots were stripped and reprobed with cDNAs corresponding to HSP89 $\beta$ (HSP90) and HSP27 genes to determine if their expression was similarly increased after restraint. Consistent with our previous observations (20), no significant increase in the expression of either of these HSPs was apparent in the adrenal glands of the stressed animals. In addition, no induction of HSP89 $\beta$

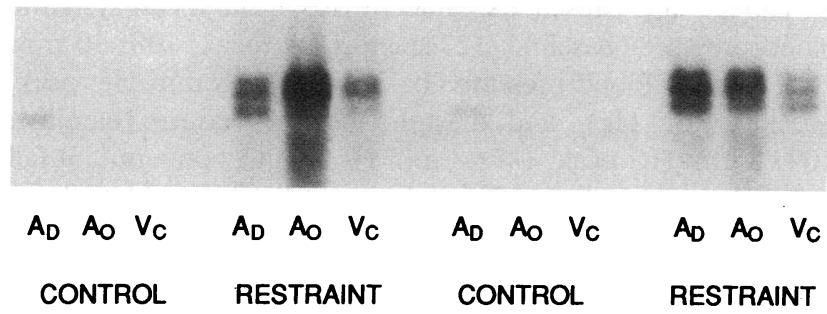

Figure 2. Northern blot analysis of HSP70 expression in total RNA ( $10 \mu \mathrm{g}$ per lane) of adrenal glands $\left(A_{d}\right)$, aortas $\left(A_{o}\right)$, and vena cavas $\left(V_{c}\right)$ harvested from individual male Wistar rats after either $60 \mathrm{~min}$ of restraint or immediately upon removal from their holding facility.
(HSP90) was apparent in the aortas of these animals. However, expression of HSP27 was markedly increased in the vessels of the restrained animals (Fig. 3 ).

To determine if induction of HSP70 mRNA resulted in increased expression of HSP70 protein, Western analysis was performed using an antibody that selectively recognizes stressinducible (but not HSC70) members of the HSP70 gene family in the rat. Samples of adrenal, aortic, and heart tissue were pooled from six separate animals at various times following restraint (Fig. 4). HSP70 protein was present in both adrenal and aortic tissues even in the absence of stress (C). However, the level of HSP70 protein increased after stress, with maximal levels apparent in both tissues 3-12 $\mathrm{h}$ after removal of the animal from the stress. In keeping with the lack of HSP70 mRNA induction by restraint in the heart, myocardial tissue showed no significant change in HSP70 protein levels following restraint stress. Heat stress (HS), however, was capable in inducing HSP70 expression in this tissue.

\section{Effect of HPA axis manipulation on restraint-induced HSP70 expression}

Hypophysectomy model. Adrenal HSP70 expression is dependent on ACTH (20). To determine if the vascular response showed a similar hormone dependence, acutely hypophysecto-

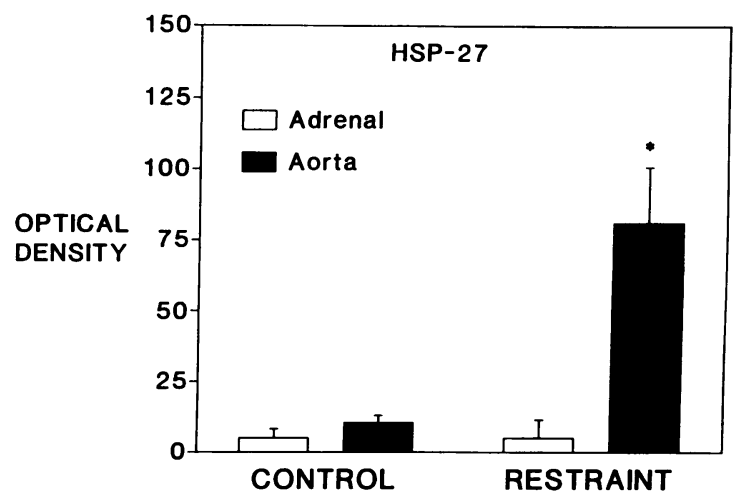

Figure 3. Effects of restraint stress upon HSP27 expression in the adrenal glands and aortas harvested from groups of restraint stressed and control male Wistar rats. The results are expressed as the mean \pm SEM relative optical density for six animals per group. A twotailed $t$ test was used to compare the control vs. restraint-induced expression. ${ }^{*} P<0.05$. 


\section{$\begin{array}{lllllll}C & 0 & 3 & 6 & 12 & 24 & 48\end{array}$}

Vessel

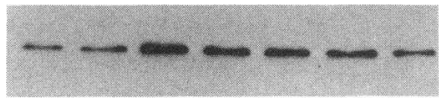

$\begin{array}{lllllll}C & 0 & 3 & 6 & 12 & 24 & 48\end{array}$

Adrenal

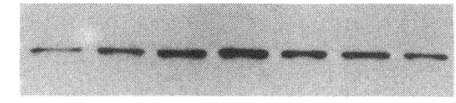

$\begin{array}{lllllll}C & 0 & 3 & 6 & 12 & 24 & \text { HS }\end{array}$

Heart

Figure 4. Western analysis of HSP70 protein expression in aortas (vessels), adrenals and hearts (left ventricle) harvested at various time points following restraint stress. Control animals $C$ were sacrificed immediately upon removal from their holding facility in the absence of restraint stress. The additional rats underwent a 60 -min restraint stress and were then sacrificed at intervals ranging from 0 to $48 \mathrm{~h}$. An isolated heart from a rat that underwent heat shock $(H S)$ exposure at $40^{\circ} \mathrm{C}$ for $30 \mathrm{~min}$ is shown as a positive control.

mized adult male rats were maintained on daily ACTH injections to prevent adrenal atrophy. After $10 \mathrm{~d}$ of treatment the animals received an acute injection of either ACTH, the synthetic glucocorticoid dexamethasone, or saline. After injection, the rats were left in their holding cages (nonrestraint) or subjected to restraint stress for $1 \mathrm{~h}$.

Daily ACTH injections maintained normal adrenal weights in all animals. Adrenals from animals that received either saline or dexamethasone injections on the day of the experiment showed no significant induction of HSP70 mRNA under either

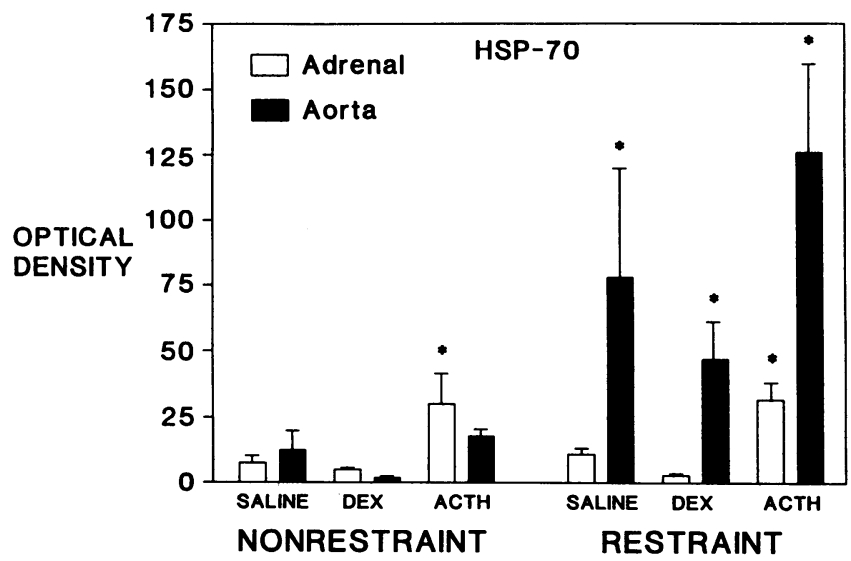

Figure 5. Influence of HPA axis on the adrenal and vascular stress response. Male Wistar rats were maintained on daily intramuscular ACTH injections $(0.25 \mathrm{U} / \mathrm{d})$ for $10 \mathrm{~d}$ after hypophysectomy. On the 11 th day the animals received an injection of saline, dexamethasone $(20 \mu \mathrm{g})$, or ACTH $(0.25 \mathrm{U})$ followed by either $60 \mathrm{~min}$ of restraint stress or their return to their holding facility for $60 \mathrm{~min}$ (nonrestraint). Results are presented as the mean \pm SEM relative optical density of the induced HSP70 transcripts from five to eight animals per group. Analysis of variance was performed and when significant $(P<0.05)$, a Newman-Keuls multiple comparison test was applied to compare individual groups. ${ }^{*} P<0.05$. nonrestraint or restraint conditions (Fig. 5). This is consistent with our previous finding that hypophysectomy eliminates restraint-induced adrenal HSP70 expression (20). Animals that received acute ACTH treatment, however, showed elevated levels of HSP70 mRNA in the adrenals under both nonrestraint and restraint conditions. Dexamethasone, like saline, did not influence HSP70 expression in the adrenal. Therefore, in the adrenal gland, ACTH, but not glucocorticoid, was capable of inducing HSP70 mRNA expression.

Elevated HSP70 mRNA levels were seen in the aortas of hypophysectomized animals after restraint regardless of the presence or absence of either dexamethasone or ACTH. Likewise, in the absence of restraint these hormone treatments had little effect on HSP70 expression in the vasculature. Thus, in contrast to the adrenal response, which shows an absolute requirement for ACTH, vascular HSP70 expression is not dependent upon the HPA axis. It is worth noting that there is a suggestion that ACTH may have potentiated restraint-induced aortic HSP70 expression, while dexamethasone appears to have reduced the magnitude of this response. These changes, however, failed to achieve statistical significance when compared to saline treated control animals.

Adrenergic manipulation model. To investigate the possible contribution of the sympathetic nervous system to restraint-induced HSP70 mRNA expression in the vasculature, intact rats were given an acute injection of either saline, the $\alpha_{1}$-adrenergic blocking agent, prazosin ( $1 \mathrm{mg} / \mathrm{kg}$ ), or the $\beta$-adrenergic blocking agent, propranolol $(20 \mathrm{mg} / \mathrm{kg})$, before $60 \mathrm{~min}$ of restraint. Animals that received a saline injection (SALINE) followed by $60 \mathrm{~min}$ of restraint showed a marked induction of HSP70 mRNA in the aorta relative to untreated rats sacrificed immediately upon removal from the housing facility (nonrestraint) (Fig. 6, top). Administration of either the $\alpha_{1}$ - or $\beta$-adrenergic blocking agent dramatically attenuated the aortic response (prazosin, 17-fold reduction; propranolol, 2.7-fold reduction compared to the restraint-stressed saline-treated control group). These adrenergic blocking agents did not affect the adrenal HSP70 mRNA response (Fig. 6, top). Adrenergic receptor blockade also reduced the level of HSP27 mRNA induction in the aorta in a parallel fashion (Fig. 6, bottom). Thus, the vascular response, but not the adrenal response, is subject to adrenergic regulation.

\section{In vivo adrenergic stimulation}

In order to directly test the effects of $\alpha_{1}$-stimulation in vivo we developed a chronic intravenous catheterization model. Central venous administration of the $\alpha_{1}$-agonist phenylephrine resulted in marked induction of aortic HSP70 mRNA (Fig. 7, left). Analysis of this effect in six control and six phenylephrine-treated animals is shown in Fig. 7 (right). This $\alpha_{1}$-adrenergic agonist also caused a significant rise in the mean systemic blood pressure (baseline, $123 \pm 6 \mathrm{~mm} \mathrm{Hg}$; peak, $168 \pm 10 \mathrm{~mm}$ $\mathrm{Hg}$ ), systolic blood pressure (baseline, $146 \pm 8 \mathrm{~mm} \mathrm{Hg}$; peak, $205 \pm 13 \mathrm{~mm} \mathrm{Hg}$ ), and diastolic blood pressure (baseline, $109 \pm 5 \mathrm{~mm} \mathrm{Hg}$; peak, $147 \pm 8 \mathrm{~mm} \mathrm{Hg}$ ) with a concomitant fall in heart rate (baseline, $353 \pm 28 \mathrm{bpm}$; nadir, $263 \pm 27 \mathrm{bpm}$ ) one min after administration. These hemodynamic parameters returned to baseline by $5 \mathrm{~min}$ after phenylephrine administration.

\section{In situ hybridization}

To identify which cells within the aorta were responsible for the elevated HSP70 mRNA levels seen in whole tissue in situ hy- 

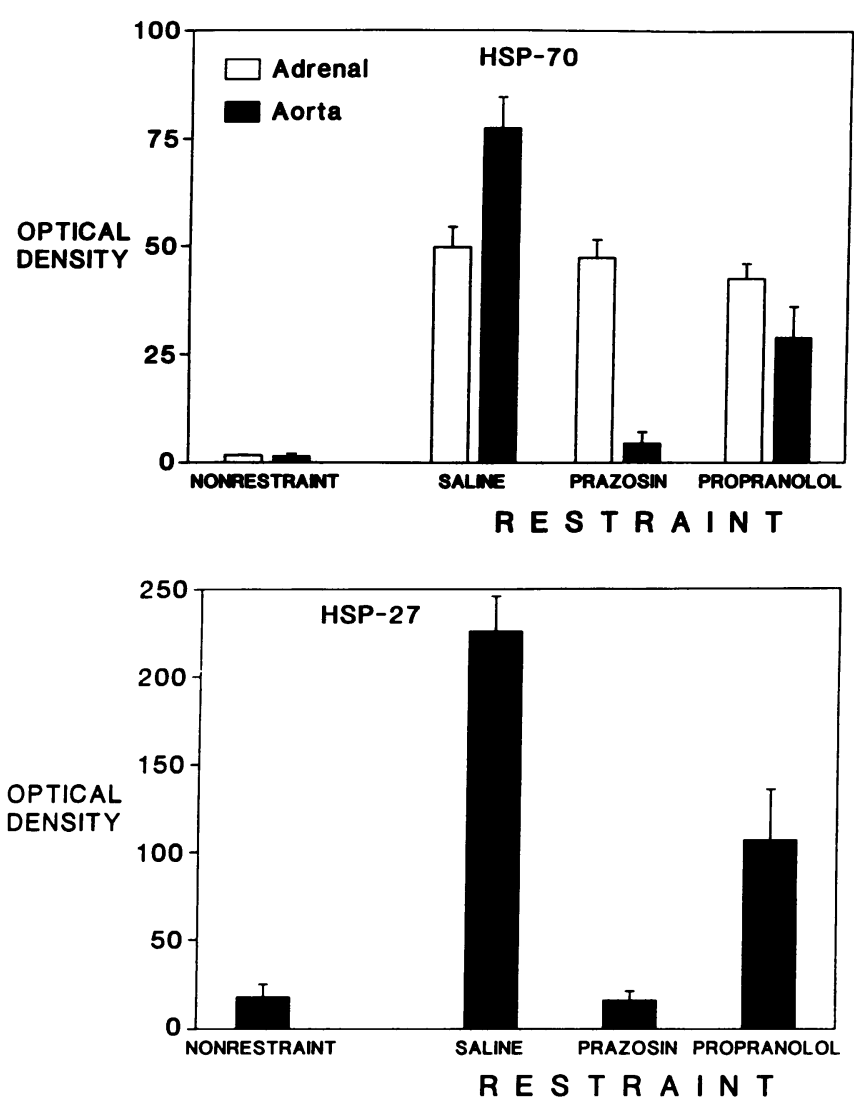

Figure 6. Effects of an acute intraperitoneal injection of saline, prazosin $(1 \mathrm{mg} / \mathrm{kg})$, or propranolol $(20 \mathrm{mg} / \mathrm{kg})$ upon adrenal and aortic mRNA expression in male Wistar rats. The agents were administered $30 \mathrm{~min}$ before a 60 -min restraint stress interval as described. Nonrestraint animals underwent sacrifice immediately upon removal from their holding facility. Results are expressed as the mean \pm SEM relative optical density. (Top) HSP70 mRNA expression in adrenal and aortic tissues ( $n=8$ per group). (Bottom) HSP27 mRNA expression in aortic tissue ( $n=3$ per group).

bridization was performed. Tissue sections from aortas of control and restrained rats were hybridized with a 30-bp oligonucleotide that recognizes only stress-inducible HSP70 transcripts (14). In keeping with the Northern analysis, strong hybridization was seen in the aortas of restrained but not control rats (Fig. 8). Expression was localized predominantely to the smooth muscle layers in the media with minimal expression in the endothelial cell layer (intima). The specificity of this in situ hybridization was demonstrated in three ways: $(a)$ competitive hybridization with 100 -fold excess cold oligonucleotide, $(b)$ pretreatment of sections with RNase before hybridization, and (c) hybridization of slides with a labeled sense oligonucleotide.
In each of these control conditions binding of the oligonucleotide to HSP70 mRNA was eliminated.

\section{Aged animal model}

Aged animals and man show diminished tolerance to stress (30-32). We have previously demonstrated that the adrenal HSP70 mRNA response to restraint is attenuated with age (20). Fig. 9 (top) shows the results of an experiment comparing HSP70 expression in the adrenals and aortas of individual young adult ( $6 \mathrm{mo}$ ) and aged Fischer $(24 \mathrm{mo})$ rats subjected to restraint. A marked attenuation of stress-induced HSP70 expression was seen in both tissues of aged rats compared to those seen in young adult animals. Quantitative analysis of HSP70 induction in young-adult $(6 \mathrm{mo})$ and aged $(24 \mathrm{mo})$ Fisher rats is shown in Fig. 9, bottom ( $n=7-8$ rats per group). The vascular attenuation was dramatic, with at least a 20 -fold diminution in aged animals. Induction of aortic HSP27 mRNA was also reduced in aged restraint stressed animals (young-adult control HSP27 relative optical density $191 \pm 27$ vs. aged restraint stressed relative optical density $40 \pm 24$ ).

Blood samples obtained at the time of sacrifice from the eight control and eight restrained animals from each age group were analyzed to determine ACTH and corticosterone (the major glucocorticoid in the rat) levels. Although both groups demonstrated typical stress hormone responses, no significant differences were seen between the young and aged animals under either basal or stress conditions (Table I).

\section{Discussion}

We reported previously that restraint results in an acute induction of HSP70 mRNA in the adrenal cortex of rats and that this response was dependent on ACTH (20). Here we demonstrate that this mild physiologically relevant stress also induces the rapid expression of HSP70 mRNA in aorta and vena cava of these rodents. In both the adrenal and vascular tissues, mRNA induction is followed by an increase in HSP70 protein expression. There are several important differences between adrenal and vascular HSP70 induction. First, the responses are differentially regulated. Vasculature HSP70 expression is not dependent on the HPA axis; rather it is subject to adrenergic control and is induced after $\alpha_{1}$-adrenergic stimulation. Adrenal expression, on the other hand, is mediated via ACTH and is not dependent on adrenergic stimulation. Second, the response in the adrenal gland appears to be restricted to members of the HSP70 gene family, whereas in the vasculature, HSP27 expression is also highly induced in response to restraint. This finding is of particular interest as HSP27 has recently been implicated in mediating sustained gastrointestinal smooth muscle contraction in response to the neuropeptide bombesin (33). It is therefore possible that HSPs serves a similar contractile function in the smooth muscle of the aorta.

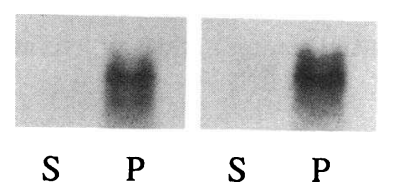

S, saline; P, phenylephrine

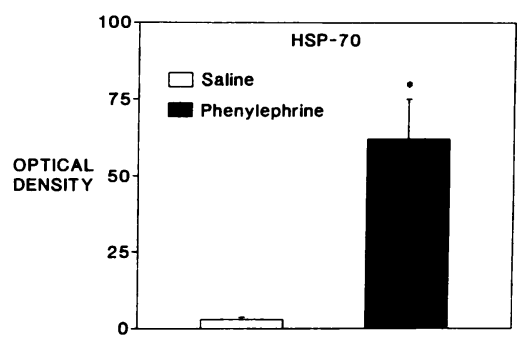

Figure 7. Effects of central venous administration of phenylephrine $(0.14 \mathrm{mg} / \mathrm{kg})$ or saline in conscious, nonrestrained male Wistar rats. (Left) Northern blot analysis of HSP70 expression in total RNA ( $10 \mu \mathrm{g}$ per lane) of aortas harvested from individual rats $60 \mathrm{~min}$ after central venous administration of either the $\alpha_{1}$-adrenergic agonist phenylephrine or saline. (Right) Summary of aortic HSP70 mRNA expression in six individual animals per group. The results are expressed as the mean \pm SEM relative optical density for the induced HSP70 transcripts. ${ }^{*} P<0.05$ by a two-tailed student's $t$ test. 


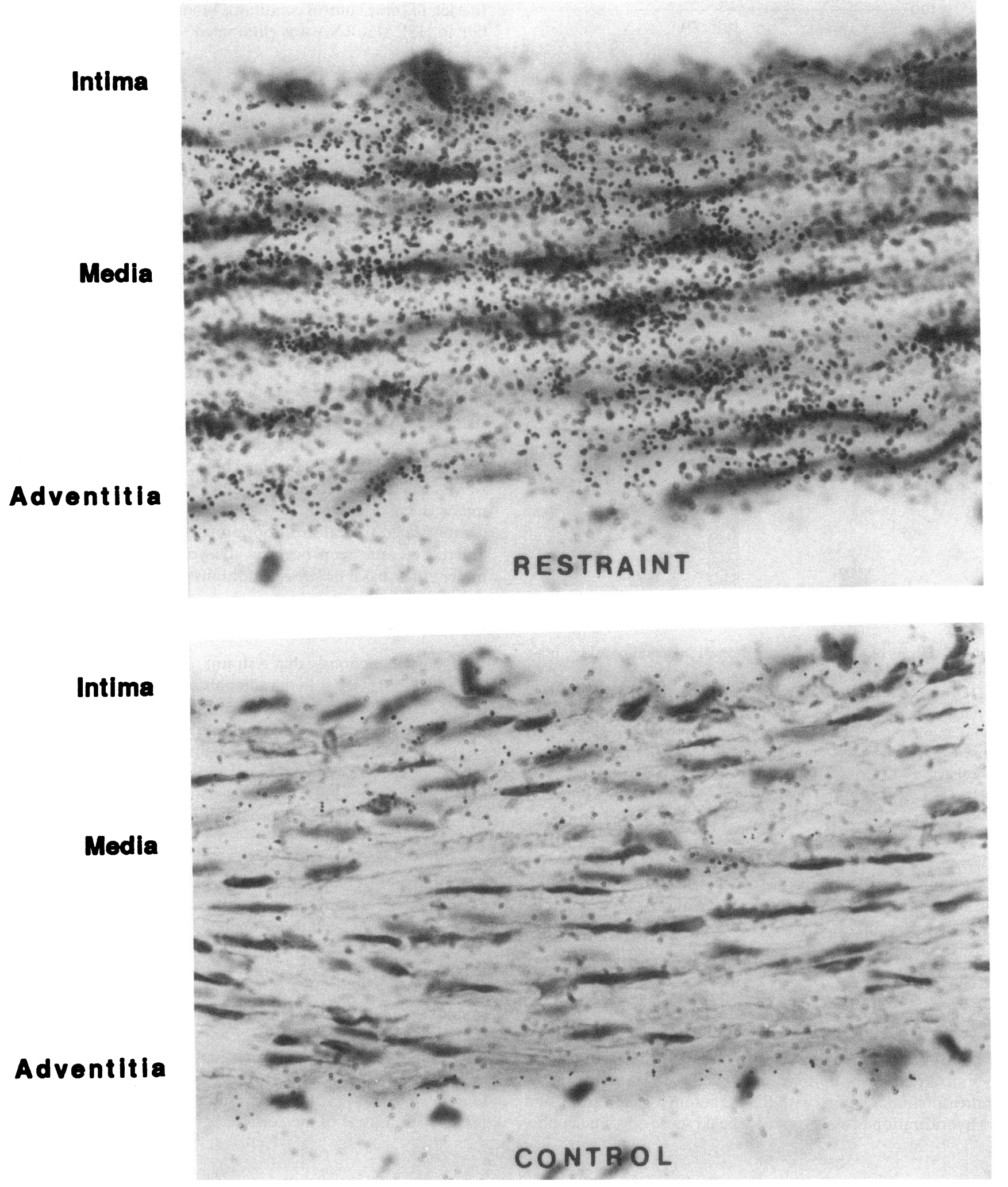

Figure 8. In situ hybridization in frozen sections of aortas obtained from restraint stressed or nonrestrained (control) animals. Sites of hybridization are indicated by the dark granules seen under microscopic examination. Original magnification, $\times 450$.

The beneficial effects of HSPs have been implied by their association with a state of thermotolerance in cultured mammalian cells. For example, a number of thermoresistant variants have been shown to express elevated levels of one or more
HSPs (34-36). In addition, over expression of recombinant HSP70 and HSP27 has been shown to confer heat resistance to cells (37-39). Conversely, competitive inhibition of HSP70 gene expression as well as microinjection of anti-HSP70 anti- 


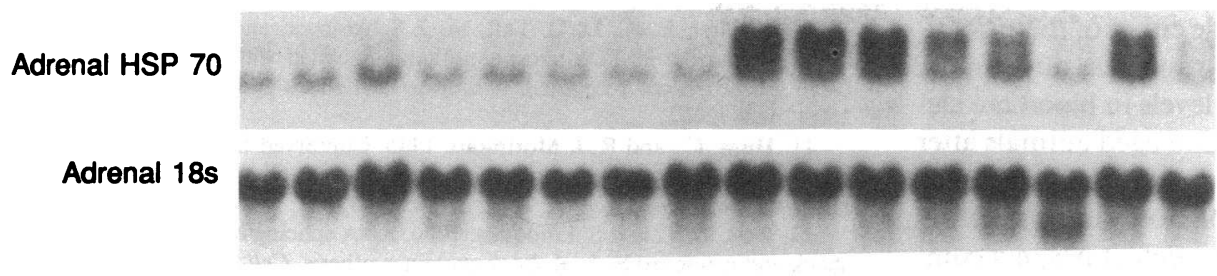

Aorta HSP 70

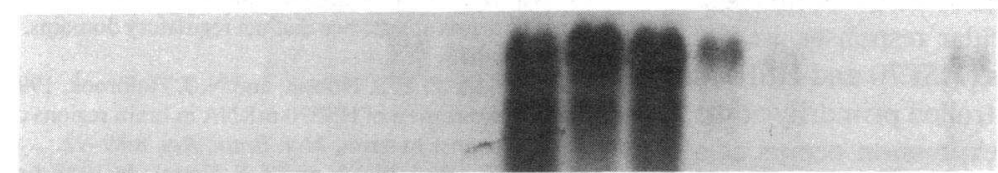

Aorta 18s

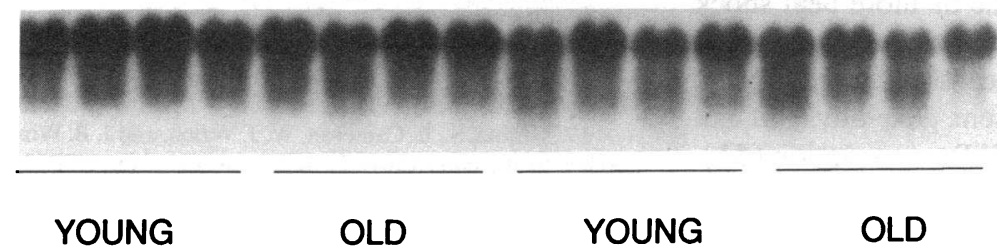

NONRESTRAINT

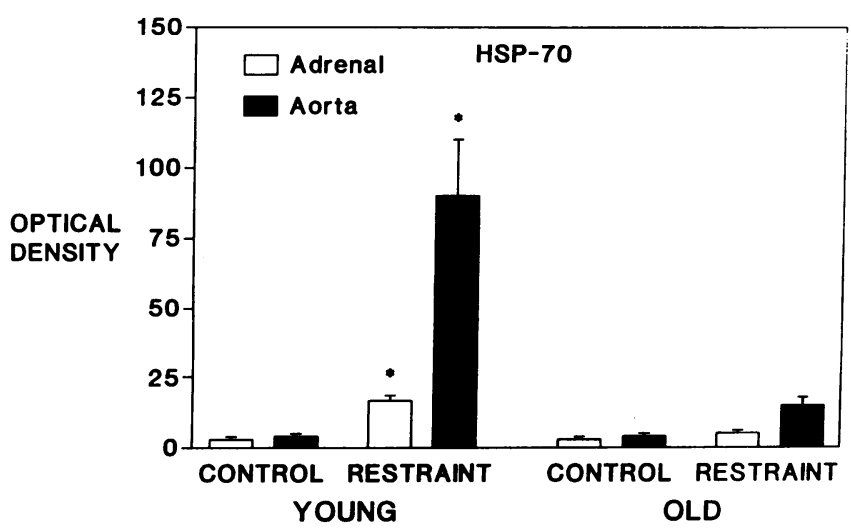

Figure 9. Adrenal and aortic HSP70 mRNA expression in individual young adult $(6 \mathrm{mo})$ and old $(24 \mathrm{mo})$ male Fischer rats. (Upper panels) Representative Northern blot in which individual lanes were loaded with $10 \mu \mathrm{g}$ per lane of total RNA. Blots were hybridized sequentially with HSP70 and 18 s probes. Animals either underwent immediate sacrifice (nonrestraint) or a $60-\mathrm{min}$ (restraint) stress. (Lower panel) Summary of adrenal and aortic HSP70 mRNA expression in groups of young (6 mo) and old ( $24 \mathrm{mo}$ ) Fischer 344 rats. Results are presented as the mean \pm SEM relative optical density for the induced HSP70 transcripts from seven or eight animals per group. Analysis of variance was performed and when significant ( $P$ $<0.05$ ), a Newman-Keuls multiple comparison test was applied to compare individual groups. bodies into cells results in greater thermosensitivity $(40,41)$. Such studies support the notion that stress-induced HSP expression is part of a protective or adaptive response and not merely an epiphenomenon $(42,43)$. In a single study in vivo, expression of HSP70 protein in rabbit retina after a mild heat stress was correlated with protection of this tissue from subsequent light damage (44). It is important to emphasize that most conditions or treatments known to elicit HSP expression are characterized by serious injury to cells or tissues. This is particularly true in vivo where induction of HSPs has been shown to occur in response to conditions such as ischemia/re-

Table I. ACTH and Corticosterone Levels in Eight Young and Eight Old Rats

\begin{tabular}{lccllc}
\hline & \multicolumn{2}{c}{ Nonrestraint } & & \multicolumn{2}{c}{ Restraint } \\
\cline { 2 - 3 } \cline { 6 - 6 } \cline { 5 - 6 } & Young & Old & & Young & Old \\
\hline $\begin{array}{l}\text { ACTH }(p g / m l) \\
\begin{array}{l}\text { Corticosterone } \\
(\mu g / d l)\end{array}\end{array}$ & $73 \pm 29$ & $59 \pm 11$ & & $397 \pm 120$ & $275 \pm 77$ \\
& $5.1 \pm 1.4$ & $4.8 \pm .7$ & & $76.5 \pm 12.5$ & $88.4 \pm 16.3$ \\
\hline
\end{tabular}

perfusion injury $(15,45)$, spinal cord trauma $(16)$, or localized injection of neurotoxins (46). Restraint stress is unique in that it results in significant induction of HSPs selectively in the adrenal gland and vasculature in the absence of any apparent damage to these tissues. These findings suggest that HSPs play a fundamental role in maintaining homeostasis. If so, it is not surprising that the adrenal and vascular tissues showed significant levels of the stress-inducible HSP70 proteins even in the absence of restraint. In earlier studies Currie and White (47) also observed high levels of stress-inducible HSP70 proteins in the adrenal glands of unstressed rats relative to that seen in other tissues. Of particular interest to our own studies, there is evidence of increased HSP70 protein expression in atherosclerotic plaques removed from diseased human carotid arteries and aortas (48). These atherosclerotic vessels have impaired contractile activity, and therefore, a diminished autoregulatory response to changes in blood volume (49).

The vascular and adrenal responses to restraint are markedly reduced in aged rodents. The reason for this attenuation is unclear. It is possible that aged rats are simply less affected by restraint. Alternatively, because both adrenal and vascular HSP70 inductions are hormone dependent, changes in HSP expression could be secondary to alterations in endocrine func- 
tion. Although we can not directly exclude either of these possibilities with respect to the sympathetic response, our results, showing that ACTH and corticosterone levels in blood are elevated to a similar degree in both young and aged animals after restraint, make them unlikely explanations for the age-related decline in adrenal HSP70 expression. A more likely explanation for this age-related decline is that the deficit lies in a common pathway leading to activation of HSPs. We favor this possibility since both the adrenal and vascular responses are depressed with age and two different HSPs (HSP70 and HSP27) are affected. HSP gene expression is controlled primarily at the level of transcription (13). Enhanced expression occurs as a result of stress-induced activation of one or more heat shock transcription factors that bind to a heat shock element in the promoter regions of HSP genes (50). Heat shock transcription factor binding to the heat shock element generally, but not always, results in an increased rate of HSP transcription (51). We have shown that binding of heat shock transcription factors to the heat shock element is activated in both the adrenal gland (20) and aortas (unpublished results) after restraint. Recent studies have provided evidence that an age-related decline in heat-induced HSP70 expression in heat-stressed senescent fibroblasts is correlated with their failure to achieve significant activation of heat shock transcription factors (52-54). It is possible that a dysfunction in the signaling mechanism(s) leading to heat shock transcription factor activation is intrinsic to the aging process. Regardless of the mechanism responsible for the age-related decline in restraint-induced HSP expression, the impaired ability of the aged animals to mount this response could contribute to the diminished stress tolerance seen in elderly individuals where there is an increased incidence of vascular disease.

\section{Acknowledgments}

We thank G. Martin, G. Wand, and S. Baylin for their insightful comments; D. Myers for preparing the manuscript; and David Goldsborough for computer graphics.

This study was supported in part by The Lilly Clinician-Scientist Award and a grant from the National Institutes of Health to Dr. Udelsman (NIDDK, K08 DK02064-01).

\section{References}

1. Selye, H. 1946. The general adaptation syndrome and the diseases of adaptation. J. Clin. Endocrinol. Metab. 6:117-230.

2. Udelsman, R., J. Ramp, W. T. Gallucci, A. Gordon, E. Lipford, J. A. Norton, D. L. Loriaux, and G. P. Chrousos. 1986. Adaptation during surgical stress: a reevaluation of the role of glucocorticoids. J. Clin. Invest. 77:1377-1381.

3. Udelsman, R., J. P. Harwood, M. A. Millan, G. P. Chrousos, D. S. Goldstein, R. Zimlichman, K. J. Catt, and G. Aguilera. 1986. Functional corticotropin releasing factor receptors in the primate peripheral sympathetic nervous system. Nature (Lond.). 319:147-150.

4. Munck, A., P. M. Guyre, and N. J. Holbrook. 1984. Physiological functions of glucocorticoids in stress and their relation to pharmacological actions. Endocr. Rev. 5:25-44.

5. Ritossa, F. 1962. A new puffing pattern induced by temperature shock and DNP in Drosophila. Experientia. 18:571-573.

6. Lindquist, S., and E. A. Craig. 1988. The heat-shock proteins. Annu. Rev. Genet. 22:631-677.

7. Morimoto, R. I., A. Tissieres, and C. Georgopoulous. The stress response, function of the proteins, and perspectives. 1990. In Stress Proteins in Biology and Medicine. R. I. Morimoto, Tissieres, Georgopoulous, editors. Cold Spring Harbor Press, Cold Spring Harbor, NY. 1-37.

8. Ang, D., K. Liberek, D. Skowyra, M. Zylicz, and C. Georgopoulos. 1991. Biological role and regulation of the universally conserved heat shock proteins. $J$. Biol. Chem. 266:24233-24236.

9. Gething, M. J., and J. Sambrook. 1992. Protein folding in the cell. Nature 355:33-44.
10. Sanchez, E. R., D. O. Toft, M. J. Schlesinger, and W. B. Pratt. 1985. Evidence that the $90 \mathrm{kDa}$ phosphoprotein associated with the untranstormed L-cell glucocorticoid receptor is a murine heat shock protein. J. Biol. Chem. 260:12358-12403.

11. Hunt, C., and R. I. Morimoto. 1985. Conserved features of eukaryotic HSP70 genes revealed by comparison with the nucleotide sequence of human HSP70. Proc. Natl. Acad. Sci. USA. 82:6455-6459.

12. Yost, H. J., and S. Lindquist. 1986. RNA splicing in interrupted by heat shock and is rescued by heat shock protein synthesis. Cell. 45:185-193.

13. Wu, B. J., R. E. Kingston, and R. I. Morimoto. 1986. Human HSP70 promoter contains at least two distinct regulatory domains. Proc. Natl. Acad. Sci. USA. 83:629-633.

14. Blake, M. J., T. S. Nowak, and N. J. Holbrook. 1990. In vivo hyperthermia induces expression of HSP70 mRNA in brain regions controlling the neuroendocrine response to stress. Mol. Brain. Res. 8:89-92.

15. Vass, K., W. J. Welch, and T. S. Nowak, Jr. 1988. Localization of the 70-k stress protein induction in gerbil brain after ischemia. Acta Neuropathol. 77:128135.

16. Gower, D. J., C. Hollman, K. S. Lee, and M. T. Tytell. 1989. Spinal cord injury and the stress protein response. J. Neurosurg. 70:605-611.

17. Minota, S., B. Cameron, W. J. Welch, and J. B. Winfield. 1988. Autoantibodies to the constitutive 73-KD member of the HSP70 family of heat shock protein in systemic lupus erythematosis. J. Exp. Med. 168:1475-1480.

18. Heufelder, A. E., J. R. Goellner, B. E. Wenzel, and R. S. Bahn. 1992 Immunohistochemical detection and localization of a 72-kilodalton heat shock protein in autoimmune thyroid disease. J. Clin. Endocrinol. Metab. 74:724-731.

19. Berberian, P. A., W. Myers, M. Tytell, V. Challa, and M. G. Bond. 1990. Immunohistochemical localization of heat shock protein-70 in normal-appearing and atherosclerotic specimens of human arteries. Am. J. Pathol. 136:71-80.

20. Blake, M. J., R. Udelsman, G. J. Feulner, D. D. Norton, and N. J. Holbrook. 1991. Stress-induced HSP70 expression in adrenal cortex: A glucocorticoid-sensitive, age-dependent response. Proc. Natl. Acad. Sci. USA. 88:98739877.

21. Udelsman, R., M. Blake, and N. J. Holbrook. 1991. Molecular response to surgical stress: specific and simultaneous heat shock protein induction in the adrenal cortex, aorta and vena cava. Surgery. 110:1125-1131.

22. Church, G. M., and W. Gilbert. 1989. Genomic sequencing. Proc. Natl. Acad. Sci. USA. 81:1991-1995.

23. Laemmli, U. K. 1970. Cleavage of structural proteins during the assembly of the head of bacteriophage T4. Nature (Lond.). 227:680-685.

24. Welch, W. J., and J. P. Suhan. 1988. Cellular and biochemical events in mammalian cells during and after recovery from physiological stress. J. Cell Biol. 103:2035-2052.

25. Anon. 1992. Phenylephrine Hydrochloride. In American Hospital Formulary Service (AHFS) Drug Information. American Society of Hospital Pharmacists, Inc., Bethesda, MD. 700-703.

26. Sorger, P. K., and H. R. D. Pelham. 1987. Cloning and expression of a gene encoding HSC73, the major HSP70-like protein in unstressed rat cells. EMBO (Eur. Mol. Biol. Organ.) J. 6:993-998.

27. Young, W. S. 1988. In situ hybridization. In In Situ Hybridization and Related Techniques to Study Cell Specific Gene Expression in the Nervous System. Society for Neuroscience, Washington, DC.

28. Giuffre, K. A., R. Udelsman, D. L. Loriaux, and G. P. Chrousos. 1988 Effects of immune neutralization of CRH, ACTH and beta-endorphin in the surgically stressed rat. Endocrinology. 122:306-310.

29. Armitage, P., and G. Berry. 1987. Statistical Methods in Medical Research. 2nd edition. Blackwell Scientific Publications, Ltd., Oxford.

30. Schock, N. W. 1986. The Baltimore Longitudinal Study of Aging. In Normal Human Aging. DHEW Publ. No. (NIH) 84-2450. NIH, Bethesda, MD.

31. Pavlov, E. P., S. M. Harman, G. P. Chrousos, D. L. Loriaux, M. R Blackman. 1986. Responses of plasma adrenocorticotropin, cortisol, and dehydroepi-androsterone to ovine corticotropin-releasing hormone in healthy aging men. J. Clin. Endocrinol. Metab. 62:767-772.

32. Sapolsky, R. M., L. C. Krey, and B. S. McEwen. 1986. The neuroendocrinology of stress and aging: the glucocorticoid cascade hypothesis. Endocr. Rev 7:284-301.

33. Bitar, K. N., M. S. Kominski, N. Hailat, K. B. Cease, and J. R. Strahler. 1991. HSP27 is a mediator of sustained smooth muscle contraction in response to bombesin. Biochem. Biophys. Res. Commun. 181:1192-1200.

34. Lazlo, A., and G. C. Li. 1985. Heat-resistant variants of chinese hamster fibroblasts altered in expression of heat shock protein. Proc. Natl. Acad. Sci. USA. 82:8029-8033.

35. Chretian, P., and J. Landry. 1988. Enhanced constitutive expression of the 27-KDa heat shock proteins in heat-resistant variants from chinese hamster ovary cells. J. Cell. Physiol. 137:157-166.

36. Anderson, R. L., I. vanKeren, P. E. Kraft, and G. M. Hahn. 1989. Biochemical analysis of heat-resistant mouse tumor cell strains; a new member of the HSP70 family. Mol. Cel. Biol. 9:3509-3516.

37. Landry, J., P. Chretien, H. Lambert, E. Hickey, and L. A. Weber. 1989. Heat shock resistance conferred by expression of the human HSP27 gene in rodent cells. J. Cell Biol. 109:7-15. 
38. Angelidis, C. E., I. Lazaridis, and G. N. Pagoulatos. 1991. Constitutive expression of heat-shock protein 70 in mammalian cells confers thermoresistance. Eur. J. Biochem. 199:35-39.

39. Li, G., L. Ligeng, Y. Liu, J. Y. Mak, L. Chen, and W. M. F. Lee. 1991. Thermal response of rat fibroblast stably transfected with the human 70KDa heat shock protein-encoding gene. Proc. Natl. Acad. Sci. USA. 88:1681-1685.

40. Riabowol, K. T., L. A. Mizzen, and W. J. Welch. 1988. Heat shock is lethal to fibroblasts microinjected with antibodies against HSP70. Science (Wash. DC). 242:433-436.

41. Johnston, R. N., and B. L. Lucey. 1988. Competitive inhibition of HSP70 gene expression causes thermosensitivity. Science (Wash. DC). 242:1551-1554.

42. Yamamori, T., and T. Yura. 1982. Genetic control of heat-shock protein synthesis and its bearing on growth and thermal resistance in Escherichia coli K-12. Proc. Natl. Acad. Sci. USA. 79:860-864.

43. Carper, S. W., J. J. Duffy, and E. W. Gerner. 1987. Heat shock proteins in thermotolerance and other cellular processes. Cancer Res. 47:5249-5255.

44. Barbee, M. S., M. Tytell, B. J. Gower, and W. J. Welch. 1988. Hyperthermia protects against light damage in the rat retina. Science (Wash. DC) 241:1817-1820.

45. Knowlton, A. A., P. Brecher, C. S. Apstein, S. Ngoy, and G. M. Romo. 1991. Rapid expression of heat shock protein in the rabbit after brief cardiac ischemia. J. Clin. Invest. 87:139-147.

46. Uney, J. B., P. N. Leigh, C. D. Marsden, A. Lees, and B. H. Anderton. 1988. Steriotaxic injection of kainaic acid into the striatum of rats induces synthe- sis of mRNA for heat shock protein 70. FEBS (Fed. Eur. Biochem. Soc.) Lett. 235:215-218.

47. Currie, R. W., and F. P. White. 1981. Trauma induced protein in rat tissues: a physiological role for a "heat shock" protein. Science (Wash. DC). 214:72-73.

48. Berberian, P. A., W. Myers, M. Tytell, V. Challa, and M. G. Bond. 1990 Immunohistochemical localization of heat shock protein-70 in normal-appearing and atherosclerotic specimens of human arteries. Am. J. Pathol. 136:71-80.

49. Lakatta, E. G. 1990. Handbook of the Biology of Aging 3rd edition. Academic Press, Inc., San Diego, CA.

50. Sorger, P. K., M. J. Lewis, and H. R. B. Pelham. 1987. Heat shock factor is regulated differently in yeast and Hela cells. Nature (Lond.). 329:81-84.

51. Jurivich, D. A., L. Sistonen, R. A. Kroes, and R. I. Morimoto. 1992. Effect of sodium salicylate on the human heat shock response. Science (Wash. DC). 255:1243-1245.

52. Liu, A. Y. C., Z. Lin, H. S. Choi, F. Sorhage, and B. Li. 1989. Attenuated induction of heat shock gene expression in aging deploid fibroblasts. J. Biol. Chem. 264:12037-12045.

53. Fargnoli, J., T. Kunisada, A. J. Fornace, E. L. Schneider, and N. J. Holbrook. 1990. Decreased expression of HSP70 mRNA and protein after heat shock in cells of aged rats. Proc. Natl. Acad. Sci. USA. 87:846-850.

54. Choi, H. S., Z. Lin, B. Li, and A. Y. C. Liu. 1990. Age-dependent decrease in heat-inducible DNA sequence-specific binding activity in human diploid fibroblasts. J. Biol. Chem. 265:18005-18011. 